EGU2020-20677, updated on 20 Aug 2021

https://doi.org/10.5194/egusphere-egu2020-20677

EGU General Assembly 2020

(c) Author(s) 2021. This work is distributed under

the Creative Commons Attribution 4.0 License.

\title{
Early Permian Paleomagnetic Result from the South Beishan (NW China) and Its Implications for the Tectonic Evolution of the SW Central Asian Orogenic Belt
}

\author{
Xin Zhu ${ }^{1,2}$, Yan Chen ${ }^{2}$, Bo Wang ${ }^{1}$, Stéphane Scaillet ${ }^{2}$, Michel Faure ${ }^{2}$, and Xinghua $\mathrm{Ni}^{1}$ \\ ${ }^{1}$ State Key Laboratory for Mineral Deposits Research, School of Earth Sciences and Engineering, Nanjing University, 210023 \\ Nanjing, China \\ ²Univ. Orléans, CNRS, BRGM, ISTO, UMR 7327, F-45071, Orléans, France
}

The Beishan Orogenic Belt plays an important role in understanding the Paleozoic tectonic evolution of the Central Asian Orogenic Belt and the final closure time of the Paleo-Asian Ocean. However, although numerous geochronologic, geochemical, and isotopic data have been obtained, no consensus has been reached yet on the Early Permian tectonic setting for this region and, thus, the final closure time of the Paleo-Asian Ocean, mainly because of the nonuniqueness of the interpretations deduced from such data base. Therefore, other methods are urgently needed to provide more constraints from different perspectives. We present here a paleomagnetic study on the Gubaoquan doleritic dike swarm in the South Beishan area. Thermomagnetic experiments and room-temperature hysteresis loops reveal that single-domain and multi-domain magnetite is the principal carrier of remanence. Anisotropy of magnetic susceptibility of studied dikes shows a horizontal magnetic foliation with a magnetic lineation generally parallel to the dikes' strike. Plagioclase ${ }^{40} \mathrm{Ar} /{ }^{39} \mathrm{Ar}$ dating result of one dolerite sample collected from the margin of a 10m-thick dike provides a cooling age at 300 284 Ma. Scanning electronic microscope observation coupled with energy-dispersive X-ray spectrometry shows that the remanence carrier is mainly euhedral without evident chemical alteration nor secondary mineral formation. Characteristic remanent magnetizations are successfully isolated from twenty dikes, and pass baked contact test. According to Deenen et al. (2011) statistical criteria, the distribution of the remanence directions reflects the contribution from paleosecular variation of the geomagnetic field. Taking all data together, the Gubaoquan doleritic dike swarm probably preserves a primary remanence. Consequently, an Early Permian paleomagnetic pole for the South Beishan can be calculated at $\lambda=80.2^{\circ} \mathrm{N}, \varphi=300.3^{\circ} \mathrm{E}, A_{95}=5.3^{\circ}$ and $N=20$. Comparisons of this new result with published ones from neighboring blocks bring us following implications for the tectonic evolution of the SW CAOB: 1. Neither relative latitudinal movement nor relative rotation can be paleomagnetically detected among Yili, Turpan-Hami, and South Beishan since the Early Permian. 2. Significant relative rotations have taken place between South Junggar and Tarim with respect to South Beishan-Turpan-Hami-Yili, respectively, since the Early Permian, corresponding to large-magnitude strike-slip displacements along mega-shear zones. 3. No obvious relative latitudinal movement has occurred between South Beishan and its neighboring 
blocks (Tarim, South Junggar, Yili, Turpan-Hami, and Dunhuang) since the Early Permian, combined with other evident, suggesting that the Paleo-Asian Ocean probably have closed before the Early Permian, and South Beishan was in a rift setting in the Early Permian. 